\title{
Coordination chemistry in electrocatalysis
}

\author{
Chunnian Shi, Beat Steiger and Fred C. Anson \\ Division of Chemistry and Chemical Engineering \\ California Institute of Technology, Pasadena CA 91125 USA
}

\begin{abstract}
Superior electrocatalysts for the reduction of $\mathrm{O}_{2}$ by fourelectrons in one step have been prepared by coordinating ammine complexes of $\mathrm{Ru}(\mathrm{II})$ to the pyridine ligand sites in cobalt tetrakis(4pyridyl) porphyrin. At least three coordinated Ru(II) centers appear to be required to obtain the four-electron reduction. When fac$\mathrm{Ru}\left(\mathrm{NH}_{3}\right)_{3}\left(\mathrm{OH}_{2}\right)_{3}{ }^{2+}$ was used to ruthenate the porphyrin, a network structure was obtained in which both terminal and bridging ruthenium centers were present.
\end{abstract}

The catalysis of electrode reactions is often accomplished by preparing active sites on electrode surfaces that serve as "electrocatalysts". Most simple electrode processes, i.e., reactions which involve the transfer of a single electron without accompanying atom or ion transfer that leads to the making and/or breaking of chemical bonds, usually do not require or benefit from electrocatalysis. The rates of such simple electrode processes are often diffusion controlled. By contrast, electrode processes that involve the transfer of several electrons, usually accompanied by the breaking of old bonds and the creation of new ones, commonly proceed slowly or not at all in the absence of electrocatalysts. Such complex electrode processes often involve high energy intermediates that must be stabilized by interactions with suitable molecules or complexes if the electrode reactions are to proceed at reasonable rates. These intermediate-stabilizing species are the electrocatalysts.

Transition metal complexes with demonstrated activities as homogeneous catalysts can sometimes be utilized as electrocatalysts by attaching them to the surfaces of electrodes. An example of this strategy is provided by the catalysis of the electroreduction of $\mathrm{O}_{2}$ at carbon or graphite electrodes in aqueous acid [1]. The reduction proceeds at unmodified graphite electrode surfaces but only at electrode potentials much more negative than the thermodynamically required values. In addition, the most common product of the reduction is $\mathrm{H}_{2} \mathrm{O}_{2}$ instead of the thermodynamically more favored product, $\mathrm{H}_{2} \mathrm{O}$. If cobalt porphyrins are introduced on the surface of graphite electrodes by, for example, irreversible adsorption, the electroreduction of $\mathrm{O}_{2}$ is catalyzed 
in the sense that it commences at much less negative potentials than are required at a bare graphite surface. However, the electrode process continues to produce only $\mathrm{H}_{2} \mathrm{O}_{2}$ as the reduction product. It is generally believed that cobalt porphyrins adsorbed on graphite serve as electrocatalysts for the reduction of $\mathrm{O}_{2}$ by coordinating the $\mathrm{O}_{2}$ molecule to the $\mathrm{Co}$ (II) center of the porphyrin. The coordinated $\mathrm{O}_{2}$ is "activated" and accepts two electrons from the electrode more readily than does an uncoordinated $\mathrm{O}_{2}$ molecule. In an attempt to induce the coordinated $\mathrm{O}_{2}$ to accept four instead of two electrons, we have been exploring the use of modified cobalt porphyrins as electrocatalysts [1-6]. Our modified porphyrins contain substituents at the four meso positions of the porphyrin ring. The substituents selected are ligands to which transition metal complexes may be coordinated. By choosing complexes which undergo facile, one-electron changes in oxidation state, we hoped to achieve a rapid, four-electron, intramolecular electron transfer to $\mathrm{O}_{2}$ molecules coordinated to the cobalt(II) centers of the modified porphyrin. Our first success was obtained with the tetraruthenated tetrapyridyl porphyrin shown in Fig. 1. At graphite electrodes coated with this porphyrin the fourelectron electroreduction of $\mathrm{O}_{2}$ to $\mathrm{H}_{2} \mathrm{O}$ occurred while the unruthenated porphyrin produced only $\mathrm{H}_{2} \mathrm{O}_{2}$ as the reduction product $[1,2]$.

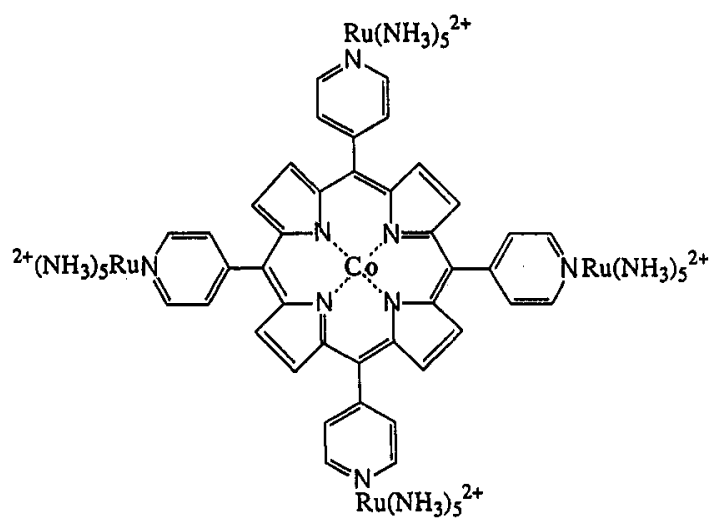

Fig. 1.

Tetraruthenated cobalt mesotetrakis(4-pyridyl) porphyrin.

A set of cobalt porphyrins having all possible combinations of phenyl and pyridyl substituents in the meso position.
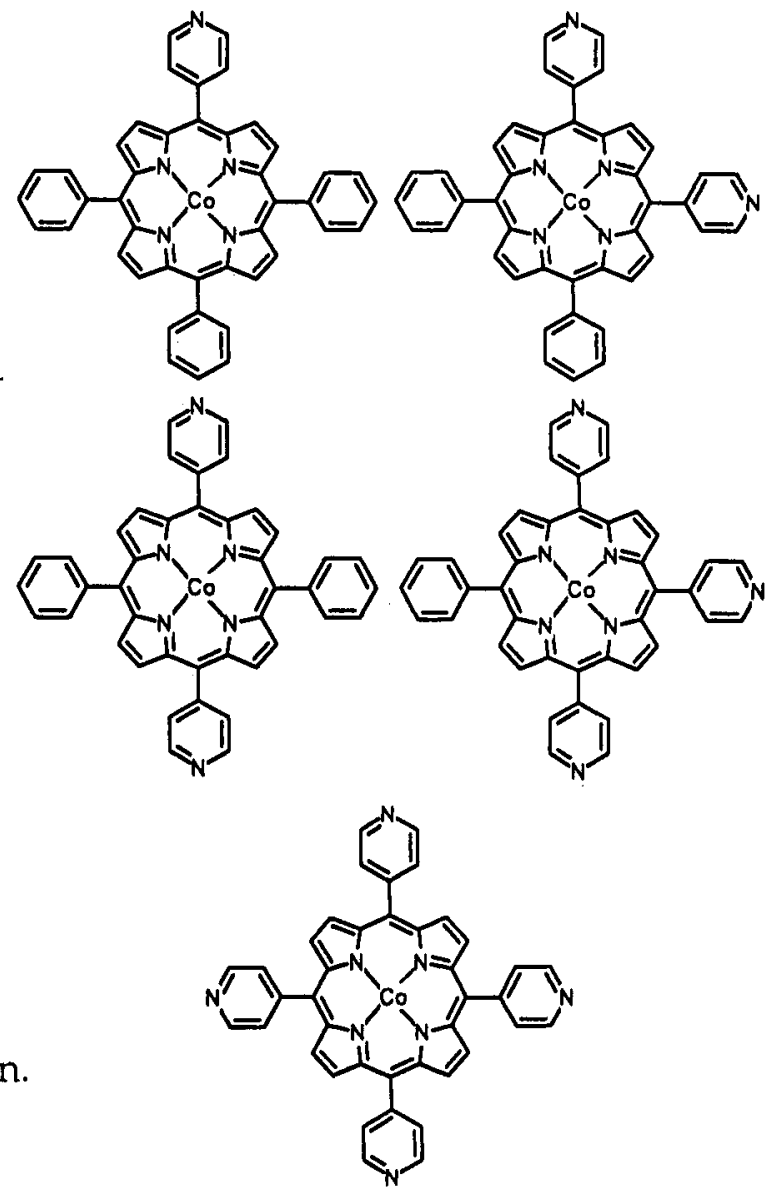

Fig. 2. 
In subsequent experiments, sets of porphyrins containing various combinations of ligand sites appended to the porphyrin ring have been synthesized and examined as electrocatalysts for the reduction of $\mathrm{O}_{2}$. For example, a set of cobalt porphyrins having mixtures of phenyl and pyridyl substituents is shown in Fig. $2 . \mathrm{Ru}\left(\mathrm{NH}_{3}\right)_{5}$ groups were coordinated to the pyridine ligands in all of the porphyrins in Figure 2 and the resulting molecules were tested as electrocatalysts for the reduction of $\mathrm{O}_{2}$. The porphyrins that contained three or four coordinated $\mathrm{Ru}\left(\mathrm{NH}_{3}\right)_{5}{ }^{2+}$ groups catalyzed the fourelectron reduction of $\mathrm{O}_{2}$ while the other three ruthenated porphyrins catalyzed only the two-electron reduction [3].

When the ruthenation of the tetrapyridyl cobalt porphyrin was carried out by reacting the porphyrin adsorbed on graphite electrodes with fac$\mathrm{Ru}\left(\mathrm{NH}_{3}\right)_{3}\left(\mathrm{OH}_{2}\right)_{3} 2+$ instead of $\mathrm{Ru}\left(\mathrm{NH}_{3}\right)_{5} \mathrm{OH}_{2}{ }^{2+}$, an apparently oligomeric coating was obtained in which both bridging and terminally coordinated $\mathrm{Ru}$ centers were present [5]. A possible structure for the coating, consistent with its electrochemical properties, is shown in Fig. 3. Such coatings catalyze the fourelectron reduction of $\mathrm{O}_{2}$ [5].

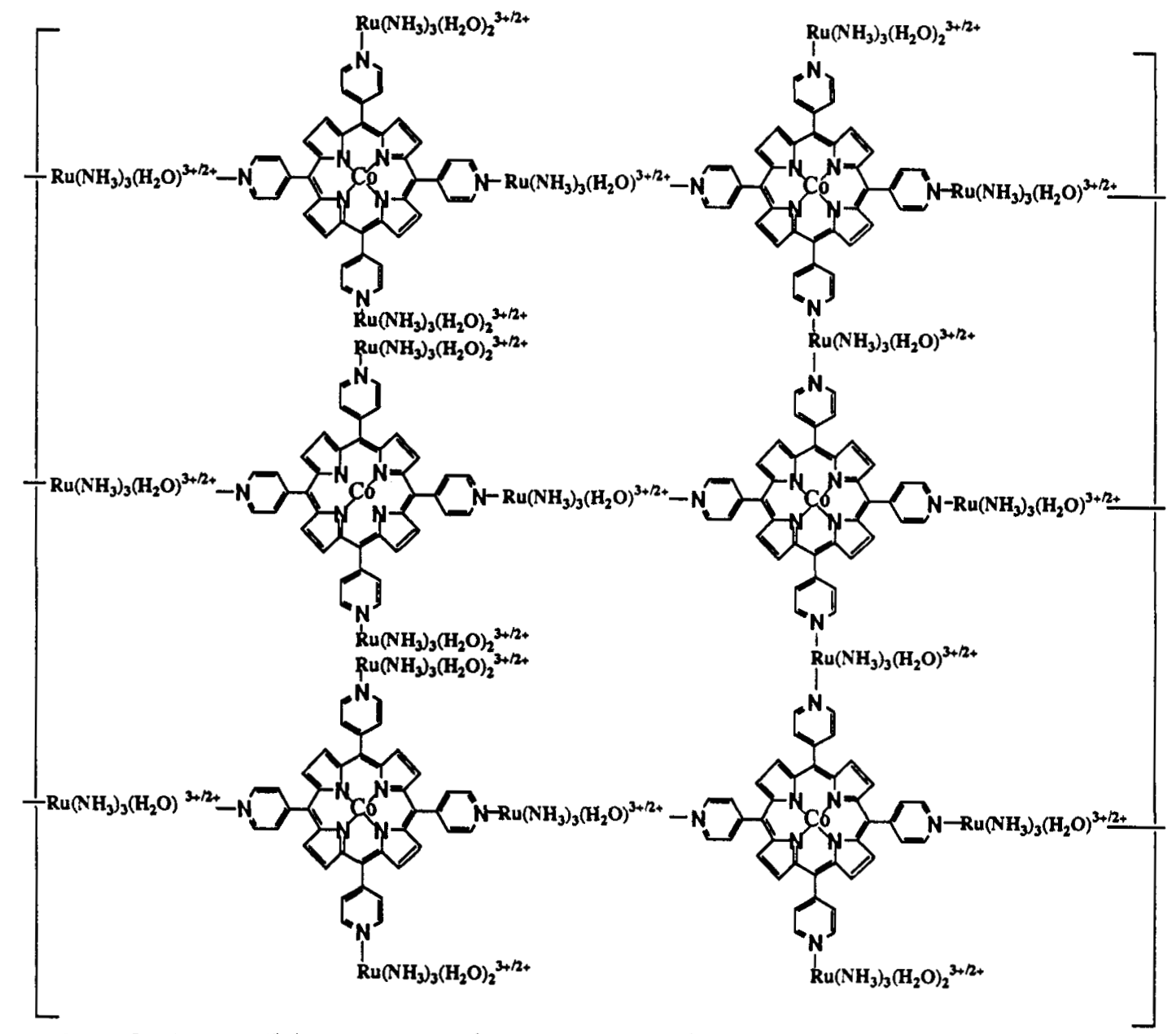

Fig. 3. A possible structure for a portion of the network of cobalt mesotetrakis(4-pyridyl) porphyrins produced by ruthenation with fac$\mathrm{Ru}\left(\mathrm{NH}_{3}\right)_{3}\left(\mathrm{OH}_{2}\right)_{3}{ }^{2+}$. 
The mechanisms through which these ruthenated cobalt porphyrins operate as four-electron reduction catalysts is thought to depend upon backbonding interactions between the $\mathrm{Ru}$ (II) centers and the porphyrin ring. These interactions are believed to affect the activation of the $\mathrm{O}-\mathrm{O}$ bond of $\mathrm{O}_{2}$ molecules that are coordinated to the $\mathrm{Co}$ (II) center in the porphyrin $[3,4]$. Rapid, intramolecular electron transfer and cycling of the ruthenium centers between oxidation states do not appear to be essential features in the catalytic mechanism $[3,6]$.

\section{ACKNOWLEDGMENTS}

This work was supported by the National Science Foundation and the Office of Naval Research/DARPA.

\section{REFERENCES}

1. C. Shi and F. C. Anson, J. Am. Chem. Soc., 113, 9564 (1991) and references cited therein.

2. C. Shi and F. C. Anson, Inorg. Chem., 31, 5078 (1992).

3. B. Steiger, C. Shi and F. C. Anson, Inorg. Chem., 32, 2107 (1993).

4. C. Shi and F. C. Anson, Electrochim. Acta, 39, 1613 (1994).

5. C. Shi and F. C. Anson, Inorg. Chim. Acta, in press, 1994.

6. B. Steiger and F. C. Anson, submitted to Inorg. Chem. 1994. 